\title{
Contentious Issues in Surrogacy: Legal and Ethical Perspectives in India
}

\author{
Kaumudhi Challa*
}

\begin{abstract}
In the past few decades, the problem of infertility among married couples has been on the rise. The advancements in medical science particularly in the field of artificial human reproductive technologies (ART) has benefitted childless couples and provided them with various options to beget a genetically related child. Among all the options available in ART, surrogacy is becoming very popular in India. This method of human reproduction raises conflicting human rights issues such as renting of womb, selection of surrogate, welfare and safety of child, commercialisation of reproduction, paternity and custody issues. Hence it is very essential to identify the various contentious issues involved in surrogacy and examine the adequacy of existing legal framework in India for the regulation of practices of surrogacy. Accordingly this paper examines the contentious issues raised by the practice of surrogacy. Further it attempts to provide some practical solution for resolving those issues.
\end{abstract}

Keywords: ART, Ethics, Law, Reproduction, Surrogacy

\section{Introduction}

In the past few decades, the problem of infertility among married couples has increased. The options available to such couples was either to adopt a child or to remain childless. The advancements in medical science particularly in the field of artificial human reproductive technologies (ART) has come to the rescue of such

* Assistant Professor, Hidayatullah National Law University, New Raipur, Abhanpur, Chhattisgarh. 
individuals and provided them with various options to beget a genetically related child.

The ART offer the advantage of begetting a child who is genetically related to at least one of the parents and thus satisfy the natural human desire to have a biological offspring. There are various options in ART like artificial insemination, in vitro fertilisation, surrogacy, and embryo transfer, etc. ${ }^{1}$ Among all these options, the method of surrogacy is becoming very popular in India and is also the most controversial method of ART. But this method of human reproduction raises a bundle of conflicting human right issues such as renting of womb, selection of surrogate, welfare and safety of the child, commercialisation of reproduction, paternity and custody issues. It also raises various ethical, religious and moral issues like playing God and commoditisation of child.

India is considered as an emerging destination for surrogacy due to fact that the surrogacy costs are very less in India when compared to other countries. This has given rise to the concept of surrogacy tourism which is developing as an industry in India. Hence it is very essential to identify the various contentious issues involved in surrogacy and examine the adequacy of existing legal framework in India for the regulation of practices of surrogacy. Accordingly this paper examines the contentious issues raised by the practice of surrogacy. Further it attempts to provide some practical solution for resolving those issues.

\section{Surrogacy: Concept and Definition}

Surrogacy is an important method of assisted human procreation for those who cannot, or choose not, to procreate in the traditional manner. ${ }^{2}$ Surrogacy, which is one of the most dramatic of the new reproductive technologies, is an arrangement by which a woman agrees to be impregnated by assisted conception, carries the

1 Paul Gahlinger, Medical Tourism Travel Guide, Types of Assisted Reproduction (Oct. 20, 2011), http:// www.hospitalscout.com /en/ MedicalTourism/guide/assisted_reproduction.html.

2 Kathryn Venturatos Lorio, Alternative Means of Reproduction: Virgin Territory for Legislation 44 LA. L. REV, 1655, 1641-1676 (1984). 
resulting foetus, and relinquishes all parental rights to the child at birth. ${ }^{3}$ According to the Warnock Report, surrogacy means, "the practice whereby one woman carries a child for another with the intention that the child should be handed over after birth." 4 Agreements may be reached between strangers, usually involving the payment of expenses; or a woman may offer to act as a surrogate for a friend or relative. The surrogate agrees ahead of time to transfer the child after birth to the infant's biological father and his wife, according to terms of a contract that was signed before the woman becomes pregnant. Some experts refer to this practice as "contractual parenting."

This method of ART is like a boon to those women who are unable to conceive due to various reasons. All women may not be able to carry their own genetic offspring. For example, a woman might be unable to ovulate or carry a pregnancy, if she has lost her womb and ovaries because of cancer or if she may have never been born with them. Similarly, a woman might be able to ovulate but unable to carry a pregnancy because of dangerously high blood pressure or risky skin diseases. By using a surrogate, such women could still raise a child that is her partners' biological child. ${ }^{5}$ A woman who cannot retain the conceived foetus due to a history of spontaneous abortion may demand her partner to go in for this arrangement to fulfil her dream of having a biological child. Also women suffering from life threatening diseases like diseases relating to kidney or multiple sclerosis may also opt for this method. ${ }^{6}$

${ }_{3}^{3}$ Katherine B. Lieber, Selling The Womb: Can The Feminist Critique Of Surrogacy Be Answered? 68 IND. L. J, 207, 205-232 Winter (1992).

${ }^{4}$ Warnock Report, Report of the Committee of Inquiry into Human Fertilization and Embryology, 1984 at 42, http:// www.hfea.gov.uk/ docs/ Warnock_Report_of_the_Committee_of_Inquiry_into_Human_Fertilisatio n_and_Embryology_1984.pdf (last visited Aug. 16, 2012).

5 Dr. Shaun D. Pattinson, Medical LaW and Ethics 271 (Sweet and Maxwell 2nd ed. 2009).

${ }^{6}$ Leslie Haberfield, SurRogate Motherhood in Victoria: What Now FOR ALtRUiSTIC SURROGACY? 37 (Monash University, 1988). 


\section{Types of Surrogacy}

There are various forms of surrogacy prevailing all over the world. Surrogacy can be classified into different types on the basis of the type of agreement entered into, financial transactions and relationships involved and on the basis of the use of genetic material.

Depending on the nature of the agreement entered into by the parties surrogacy can be classified as formal or informal surrogacy. In case of formal surrogacy arrangements, the nature and terms of the agreement between the surrogate and the commissioning couple are clearly specified. Informal surrogacy arrangements are often vague and uncertain because there is no specification with respect to terms and conditions.

Depending upon the financial transactions between the surrogate mother and commissioning parents' surrogacy can again be classified as Commercial and Altruistic Surrogacy. Commercial surrogacy involves payment of money or other benefits to the surrogate mother while Altruistic surrogacy does not involve any financial transaction and is usually between friends and relatives.

Depending on the use of genetic material surrogacy can also be classified as partial or total. Partial surrogacy means the surrogate mother contributes genetic material to the resulting child. Total surrogacy refers to the implantation of foreign genetic material into a woman who gestates the child for another couple who are the genetic parents. ${ }^{7}$

Thus the entire procedure of surrogacy is very complicated, expensive and involves tremendous psychological impacts. For most couples, surrogacy is the last resort. Many have tried artificial insemination, in vitro fertilization, both, or many other assisted reproductive technologies. The legality of surrogacy is also unclear

7 Glenda Emmerson, Surrogacy: Born For Another, RESEARCH BULLETIN NO 8/96, QueENSLAND PARLIAMENTARY Library, Publications AND RESOURCES SECTION, BRISBANE, SEPTEMBER 1996,

http:/ / 210.8.42.131/documents/explore/ResearchPublications/researchB ulletins/rb0896ge.pdf (last visited Aug. 21, 2012). 
because surrogacy contracts are considered as illegal by some countries, and also the rights and responsibilities of the parties of the contract are ill-defined. Hopeful parents face many serious obstacles in their quest for parenthood long before the intended child is born. Still, many women and men desire to have children inspite of all the difficulties, legal, ethical, moral and religious. ${ }^{8}$ All these difficulties are raising various contentious issues.

\section{Contentious Legal and Moral Issues in Surrogacy}

\section{Access to Surrogacy}

The right to procreation is a fundamental basic human right. ${ }^{9}$ However the increasing use of technology raises the important question as to whether surrogacy can also be used as a right and who can avail this right? Traditionally, surrogacy is considered as the last option available for procuring a child by married infertile couples. However use of surrogacy become a contentious issue due to the use of surrogacy by other persons also like divorced, widowed, single, same sex couples, aged, disabled who are interested to have a child. Increase use of technology by these people to beget a child would have a great impact on the social structure, meaning of family, institution of marriage and it will affect the social norms, morals and ethics in society. Further, the use of surrogacy by aged and disabled persons will raise the issues of maintenance and welfare of the child. Therefore it is necessary to determine the criteria regarding the use of surrogacy by individuals other than married infertile couples.

\section{Harm to Surrogate Mother}

Most Indian women act as surrogate mothers due to poverty or other economic necessity. However, surrogacy technology may involve some complications and cause harm to the health and life

8 Aneesh V. Pillai, Surrogacy: A Daunting Challenge to Indian Legal System (Aug. 27, 2011) (unpublished manuscript) (on file with author).

${ }^{9}$ International Convention on the Protection and Promotion of the Rights and Dignity of Persons with Disabilities, Dec. 13, 2006, 46 I.L.M. 443, art. 23 (1) (b); see also Protocol to the African Charter on Human and Peoples' Rights on the Rights of Women in Africa, Nov. 25, 2005, art. 14. 
of the surrogate mother. ${ }^{10}$ This raises the important issue of liability for the harm caused or suffered by the surrogate mother. If there is no medical negligence on the part of the doctors and other paramedical staff, it would be difficult to fix the liability and thereby indemnify the loss suffered by the surrogate mother.

\section{Validity of Surrogacy Contracts}

The law relating to surrogacy contracts is vague and uncertain. Different countries have different laws with respect to validity and enforceability of surrogacy contracts. Some of the countries consider these contracts as illegal while some others have their own laws for their regulation. In India, it is generally criticised that surrogate contracts are opposed to public policy because they involve the use of a womb by a women for begetting a child to be handed over to the other party on payment of money, which is like renting of a womb and selling of the child. It is to be noted that a contract opposed to public policy is a void contract according to the Indian Contract Act, 1872.11 Thus the legality of surrogate contracts is uncertain.

\section{Interest of the Child}

Surrogacy generally involves payment of money to the surrogate mother for delivering and handing over the child to the commissioning parents. Thus it is criticised as equivalent to buying and selling a child. It is also argued that it would lead to selection of sex and traits in a child, i.e. creation of designer babies. Thus surrogacy would result in treating a child as a product which is considered as morally wrong and unethical. It is also observed that the process of surrogacy involving in vitro fertilisation usually

10 Matthew Tie, Oh Baby Baby: The Problem of Surrogacy, in BIOETHICS RESEARCH NOTES 19(1) http:// www.bioethics.org.au/ Resources/ Online \%20Articles/Opinion \%20Pieces/1901\%20Oh\%20Baby\%20Baby $\% 20$ The \%20Problem\%20with\%20Surrogacy\%20MT.pdf (last visited Aug. 21, 2012); see also M M Tieu, Altruistic Surrogacy: The Necessary Objectification of Surrogate Mother, J. MED ETHICS 35 (3) http://philpapers.org/rec/TIEAST (last visited Aug. 21, 2012).

11 The Indian Contract Act, 1872, §23. 
results in birth of triplets or quadruplets. ${ }^{12}$ This may harm the interest of the child, as the commissioning parents may not be in a position to look after such number of children born against their wish. Further, it is also argued that surrogate children may be born with defects. Another contentious issue in this process is the determination of parentage and custody of child. ${ }^{13}$ Surrogacy involves participation of three or four or five adults. So it is difficult to determine the parentage of child.

\section{Surrogacy Degrades the Dignity of Woman}

Right to dignity is one of the inherent and cherished rights of every human being. It is argued that surrogacy degrades the inherent dignity of a woman. Surrogacy involves the use of a woman's body for producing a baby which is handed over to the commissioning parents. During the term of pregnancy, the surrogate mother has to abide by the conditions laid down in the contract and has no right to take any decision affecting her body. Moreover the surrogate mother also considers pregnancy as a means of earning money and tries to avoid developing a special bond with the child in her womb. Thus the natural mother-child bond is either absent or suppressed and the entire process is viewed as a commercial transaction. The critics argue that the women's body is reduced to being an incubator ${ }^{14}$ or breeder machines ${ }^{15}$ and thus it degrades the dignity of women.

${ }^{12}$ See Southern Cross Bioethic Institute, Inquiry into Legislation on Altruistic Surrogacy in NSW,

http:/ / www.parliament.nsw.gov.au/Prod/parlment/committee.nsf/0/6 a6e8db9f2366acbca2574ea0018b4b0/\$FILE/Submission\%2014.pdf (last visited Aug. 21, 2012).

13 See generally O'Brien \& Shari, Commercial Conceptions: A Breeding Ground for Surrogacy 65,

https://litigationessentials.lexisnexis.com/webcd/app?action=Document Display\&crawlid $=1 \&$ doctype $=$ cite $\&$ docid $=65+$ N.C.L. + Rev. $+127 \&$ srctype $=$ smi\&srcid=3B15\&key=672427e9a88973a857df0f5802bbf5c1 (last visited Aug. 21, 2012).

${ }^{14}$ Larry Ogalthorpe Gostin, Surrogate Motherhood: Politics and PRIVACY, 326 (Indiana University Press 1990). 


\section{Child's Right to Know his Origin}

Article 7 (1) of the Convention on the Rights of the Child (CRC), 1992 emphasises that a child has the right to know about his or her origin. This means that the authorities have to maintain proper records pertaining to the origin of a child. A duty is also cast on the doctors, hospitals and the parents to provide necessary information as and when required. The genetic information is necessary for diagnosing and treating certain diseases as well as to avoid consanguineous and incest marriages. It is to be noted here that, in case of surrogacy the disclosure of such information may have adverse consequences on the child as well as surrogate mother and commissioning parents. It is argued that once the child knows about the history of his or her birth, the child may go back to the genetic mother or surrogate mother as the case may be. It may also affect the child psychologically and it can cause mental harm to the surrogate mother as well as commissioning parents. However, there is no specific law which regulates the disclosure of genetic information to the child in India.

\section{Playing God}

Traditionally a child is considered as a gift of God. The act of procreation was also considered as a sacred obligation to be undertaken by the couples for begetting a child. Before the advancement of medical technology the only option available to childless couple was either to adopt a child or to accept the childlessness as a decision of God. The developments in science and medical technology have created a revolution by enabling the childless couples to beget a child which is genetically related to at least one of the parent. Though science has been a boon to childless couples, the increasing use of technology and experimentation for creating babies with specific traits and characteristics is being criticised. The critics argue that by interfering with the natural

15 See Melanie Jo DeMaeyer, Living Incubators: Arguing for Pregnant Women's Autonomy and Bodily Integrity in an Age of Ever-increasing Reproductive Technologies,

http:/ / acumen.lib.ua.edu/content/u0015/0000001/0000296/u0015_0000

001_0000296.pdf, (last visited Aug. 21, 2012). 
reproductive process, the man is playing the role of God. ${ }^{16}$ This is considered as a moral, ethical and religious wrong.

\section{Wastage of Embryo}

Surrogacy is an artificial reproductive technology, in which firstly the method of in vitro fertilisation is used for fertilising the egg with sperm and developing an embryo, and secondly, the developed embryo is transferred to the womb of surrogate mother. This process generally involves repeated attempts and trials so as to ensure success. Thus it involves wastage of embryo, eggs and semen. ${ }^{17}$ It is argued that, the life begins at conception and hence this wastage of embryos is similar to murder.

\section{Conclusion}

Surrogacy as a method for begetting a child has been practiced from ancient times. However, the developments in science and technology have led to the increased use of this method for begetting a biological child not only by infertile couples but also by anyone who wishes to have a child. This increasing use of surrogacy has raised legal, ethical, moral and religious debates all over the world. In India, surrogacy is becoming a booming industry due to the fact that surrogate mothers are easily available and the entire cost of this method is very less when compared to other countries. It is pertinent to point out here that, the various issues raised by this method of ART have not been adequately addressed by Indian legal system. In India, there is no specific law which regulates the issues raised by surrogacy. An attempt was made by Indian Council of Medical Research to adopt certain guidelines for the regulation of surrogacy. But these are not sufficient and they lack legal force. Another significant attempt in this regard is the Assisted Reproductive Technology Bill, 2010.

16 See generally Grayce P. Storey, Ethical Problems Surrounding Surrogate Motherhood (Oct. 20, 2011),

http://www.yale.edu/ynhti/curriculum/units/2000/7/00.07.05.x.html/.

17 See K. R. Mao, Some Ethical Aspects of In Vitro Fertilization and Research on Human Embryos (Oct. 20, 2011),

http:/ / sunzi.lib.hku.hk/hkjo/view/21/2100209.pdf. 
However it is yet to become a statute and does not deal with the method of surrogacy in detail. However, for the effective regulation and resolving the various contentious issues raised by surrogacy, the following suggestions are given below:

1. There is an urgent need to have a specific legislation for the regulation and control of surrogacy in India. It should take into account issues like access to surrogacy, liability issues, interest of the child, parentage of child, etc.

2. It is in the best interest of the child and the society that the access to surrogacy should be limited to infertile married heterosexual couples.

3. In cases of harm to surrogate mother the liability should be fixed to commissioning parents.

4. It is to be noted that, while making any regulations for surrogacy, utmost importance should be given to the child.

5. The terms and conditions of contract of surrogacy should be clearly laid down and a proper balance should be maintained between the duties of surrogate mother and the protection of dignity and her rights.

Surrogacy like every other technology also has its own pros and cons. If it is used wisely, it would bring happiness to millions of childless couples all over the world. But if it is used in a careless or reckless manner and without any proper control it would have an adverse impact on the very institution of family and society and result in degradation of human relationships and values. 